\title{
Além da "Monocultura Institucional": instituições, capacidades e o desenvolvimento deliberativo*
}

PETER EVANS***

\section{Introdução}

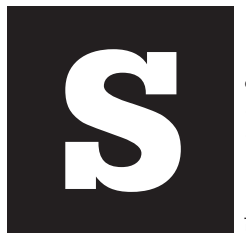

ituar um conjunto de estratégias de desenvolvimento aquelas que utilizam sistemas institucionali-zados de deliberação popular para alocar bens coletivos - dentro de uma estrutura maior da teoria do desenvolvimento contemporâneo é o propósito deste artigo. A "nova teoria do crescimento" e a análise organizacional moderna do crescimento econômico levaram a teoria do desenvolvimento para longe de um foco centrado no acúmulo de capital, em direção a um entendimento mais complexo das instituições que tornam o desenvolvimento possível. A mais acentuada conseqüência estratégica dessa "virada institucional" foi o surgimento da "Monocultura Institucional" - a imposição de versões idealizadas de instituições anglo-americanas baseadas em planejamentos, cuja aplicabilidade presumivelmente transcende as culturas e circunstâncias nacionais. Os resultados frustrantes da monocultura institucional sugerem que a "virada institucional" tome outras direções. O "enfoque da capacidade" de Amartya Sen defende com firmeza um foco em instituições que envolvem "debate e intercâmbio públicos". Os exemplos de Porto Alegre, no Brasil, e Kerala,

\footnotetext{
* Beyond "Institutiona/Monocropping": Institutions, Capabilities, and Deliberative Development. Traduzido por Fabiano Bruno Gonçalves e revisado por Patrícia Lessa Flores da Cunha. NET - Núcleo de Estudos de Tradução Olga Fedossejeva, Instituto de Letras, UFRGS.

** Professor da Universidade de Berkeley, Califórnia. PhD. Endereço eletrônico: pevans@socrates.berkeley.edu
} 
na Índia, reforçam a idéia de que o "desenvolvimento deliberativo" é promissor em termos de desenvolvimento.

Perspectivas teóricas sobre desenvolvimento migraram para um admirável mundo novo onde "o desenvo/vimento não é mais visto principalmente como um processo de acúmulo de capital, mas sim como um processo de mudança organizacional" (Hoff e Stiglitz, 2001, p. 389). A teoria mais sofisticada de desenvolvimento a surgir desse processo leva a muitas direções. Uma delas é a idéia de "desenvolvimento deliberativo". O objetivo do debate que segue é recapitular brevemente o percurso teórico voltado às estratégias de desenvolvimento deliberativo e, então, explorar discussões que considerem o efeito de tais estratégias.

A teoria do desenvolvimento começou a se desviar do "fundamentalismo do capital"1 há quase 50 anos, primeiramente enfatizando a "tecnologia" e, posteriormente, o papel de idéias que de forma mais geral e final enfocam as "instituições". Esse movimento reforçou a convicção de que a qualidade de instituições básicas de governança deveria ser considerada o elemento-chave para fomentar o crescimento. Infelizmente, a implementação dominante dessa percepção, que vem tentando impor planejamentos institucionais uniformes nos países do Sul - o que denomino "monocultura institucional" -, tem produzido resultados frustrantes. Mesmo para os que não concordam com o julgamento ${ }^{2}$ pessimista de William Easterly de que "os trilhões de dólares gastos desde a década de 1960, juntamente com os esforços de conselheiros, de provedores estrangeiros de assistência econômica, do Fundo Monetário Internacional e do Banco Mundial, todos falharam em alcançar os resultados desejados", é evidente a necessidade de respostas mais imaginativas para a questão institucional.

Procurando novas perspectivas sobre a questão institucional, voltome para o "enfoque da capacidade" de Amartya Sen. O enfoque da capa- 
cidade põe a questão da escolha social em primeiro plano e argumenta que as instituições deliberativas - debate e intercâmbio públicos - devem ser centrais para qualquer conceituação de desenvolvimento, tanto como um fim valorizado em si mesmas como o único meio totalmente legítimo de avaliar outros fins. As eleições e os direitos civis são a base essencial para a construção de instituições deliberativas eficientes, mas a tendência crescente em direção a uma versão "esvaziada" (hollowed out) da democracia no Sul (Yusuf e Stiglitz, 2001, p. 249) reivindica uma resposta institucional mais substancial. A "democracia deliberativa" oferece uma institucionalização mais substancial do "debate e intercâmbio públicos".

O impacto potencial de desenvolvimento da democracia deliberativa é explorado no exame de dois exemplos bem conhecidos - o estado de Kerala, na Índia e a cidade de Porto Alegre, no Brasil. Esses casos sugerem diversas propostas interessantes. Primeiramente, as instituições deliberativas parecem, de fato, ser eficazes ao engajarem a energia dos cidadãos comuns no processo de escolha social, satisfazendo, assim, o critério do "fimem-si-mesmo" enfatizado pelo enfoque de Sen. Em segundo lugar, essas instituições parecem aumentar a disposição dos cidadãos de investir em bens públicos e melhorar a distribuição dos mesmos bens. Uma vez que tais bens coletivos (p.ex., serviços de saúde e educação, infra-estrutura do transporte) são também meios de promover a produtividade, a contribuição potencial para o crescimento a longo prazo é implícita. Reduzir a violência e a corrupção no processo de governança é outro benefício intrinsecamente valioso e potencialmente intensificador do crescimento. Dois exemplos não podem atestar essas proposições, mas os ganhos potenciais do desenvolvimento são, não obstante, intrigantes.

A discussão não é a de que as instituições deliberativas eficazes podem, por si próprias, capacitar os países pobres à realização de atividades impossíveis - criar rendas sem capital e tecnologia. A discussão é a de que as instituições deliberativas são complementos essenciais para outros insumos. Ajudam a fornecer as condições subjacentes de governança que 
tornam eficazes capital e tecnologias. Aumentam a possibilidade de que os empréstimos financeiros institucionais "assimilem" o ambiente local. Fornecem uma base mais sólida para avaliar as prioridades de desenvolvimento. Igualmente importante, estratégias deliberativas expandem o que o desenvolvimento oferece, dando aos cidadãos a oportunidade de exercer a capacidade humana fundamental de fazer escolhas.

As restrições nas estratégias de desenvolvimento impostas por teorias econômicas de crescimento não podem mais ser utilizadas como justificativas para a não-exploração desse caminho para o desenvolvimento. Pelo contrário, o que Hoff e Stiglitz (2001) denominam "teoria econômica moderna" acarreta uma ênfase geral sobre as instituições, enquanto as contribuições teóricas de Amartya Sen sobre o "enfoque da capacidade" nos conduzem especificamente na direção de instituições deliberativas. Os dois autores justificam inteiramente abordar com atenção especial o problema da institucionalização do desenvolvimento deliberativo.

\section{Crescimento impulsionado por idéias e instituições}

O "fundamentalismo do capital" tem forte apelo intuitivo. O modelo de Harrod-Domar e as prescrições de políticas que o acompanham têm uma elegância e uma simplicidade atraentes. Qualquer país poderia enriquecer se pudesse aumentar suas economias domésticas, que se tornariam, então, investimentos, gerando um crescimento em rendas futuras proporcional à parcela de investimento aumentada. Se as taxas de economias domésticas não pudessem ser aumentadas, o financiamento externo preencheria a lacuna. O fundamentalismo do capital era especialmente otimista do ponto de vista dos países pobres. O capital deveria fluir de onde fosse relativamente abundante e, portanto, recebesse retornos menores (países ricos) para onde fosse escasso e, conseqüentemente, recebesse retornos maiores (países pobres). Os países ricos sofreriam mais pela diminuição dos rendimentos. O alcance da igualdade seria a previsão clara. 
Infelizmente, o fundamentalismo do capital não funcionou - nem teórica nem empiricamente. Robert Solow (1957) mostrou que o fundamentalismo do capital não teve sentido teórico nem justificou a trajetória a longo prazo do crescimento americano. ${ }^{3}$ Os supostos benefícios ao Sul não se materializaram na prática. $\mathrm{O}$ capital tendia a fluir mais entre os países ricos do que dos ricos para os pobres. Instituições internacionais, na tentativa de compensar esse desequilíbrio com empréstimos e concessões de financiamento, descobriram, para sua frustração, que mais capital, não raro, trazia poucos benefícios. King e Levine (1994, p. 286) concluem que

(...) há pouco apoio para a idéia de que o fundamentalismo do capital deveria guiar nosso programa de pesquisas e aconselhamento de políticas. (...) diferenças internacionais em capital por pessoa explicam pouco sobre as diferenças em produto por pessoa entre países. Além do mais, enquanto o quociente de investimento para o PNB é intensa e fortemente associado ao crescimento econômico, há pouca razão para se crer que isso constitui evidência de que o investimento crescente causará crescimento mais rápido. De fato, resultados recentes indicam o oposto: o crescimento econômico favorece investimentos e economias, e não o contrário.

Enquanto o papel do investimento permanece uma questão central na teoria do desenvolvimento, ${ }^{4}$ o consenso destituiu o capital de sua condição de "tiro mágico" para torná-lo um fator a mais em uma mistura complexa. ${ }^{5}$

3 Até mesmo Evsey Domar concordou. Ver Domar, 1957, p. 7-8; Easterly, 2001a, p. 28.

4 Ver Jorgenson et al., 1987, DeLong e Summers (1993), Kim e Lau, 1994, 1995 e Young, 1995.

5 Ver Blomstrom, Lipsey \& Zejan (1996); Barro (1997); Lin e Lee (1999); Easterly (2001a); Hoff e Stiglitz (2001, p. 428); Meier e Rauch (2000, cap. 3). 
A "nova teoria do crescimento", com sua ênfase em crescentes retomadas de idéias, ${ }^{6}$ veio agora para dominar debates teóricos sobre crescimento, a despeito das complexidades e incertezas que isso impõe sobre decisões políticas. Mais uma vez, as premissas básicas fazem sentido intuitivo. A lógica sombria dos rendimentos decrescentes, que limita as estratégias de desenvolvimento baseadas no capital físico (e ainda mais completamente aquelas que são baseadas em terra e recursos naturais), não se aplica a conhecimento e idéias. Já que idéias são bens "não-rivais", simultaneamente utilizáveis por quaisquer dos diferentes agentes econômicos, o uso delas é naturalmente sujeito a rendimentos crescentes (Romer, 1993a, p. 63). Você e eu não podemos usar o mesmo carrinho-de-mão ao mesmo tempo mas, uma vez que alguém nos dá a idéia, você, eu e todos os nossos primos podemos construir carrinhos-de-mão. Uma vez que uma idéia aplicável ou um certo conhecimento é criado, o custo de utilizá-la(o) de novo é essencialmente zero; assim, os rendimentos desse uso aumentam cada vez que ele é utilizado.

Para os países ricos, as implicações da nova teoria do crescimento são otimistas. Não há limites teoricamente óbvios no crescimento, ou mesmo na taxa de crescimento. Na verdade, o crescimento deveria acelerar com o tempo à medida que o conjunto de idéias se acumula. A mudança de rendimento do consumo para a poupança deixa de ser condição sine qua non do desenvolvimento aumentado. Para os países pobres, entretanto, as implicações são mais ambíguas. Se os países pobres fossem capazes de simplesmente começar a usar o conjunto de idéias que os países ricos já acumularam, suas taxas de crescimento subiriam, na teoria, vertiginosamente. Na prática, aproveitar-se das idéias de outras pessoas é tudo, menos algo simples. Para começar, embora idéias sejam bens não-rivais, seus rendimentos podem ainda ser transformados em propriedade, controlados

6 Ver Romer (1986, 1990, 1993a, 1993b, 1994) e Lucas (1998). Para resumos recentes, ver Aghion e Howitt (1999) ou Easterly, (2001a, caps. 3, 8, 9). 
e até mesmo monopolizados (cf. Romer, 1993a, p. 71-72). Disputas atuais entre países ricos e pobres acerca de direitos de propriedade intelectual são indicativos das tensões de como os rendimentos provenientes de idéias serão distribuídos. Ainda mais fundamentalmente, a proposta de armazenar rendimentos a partir de idéias depende, na maioria dos casos, da capacidade de articulá-los com inputs complementares, como capital, mão-de-obra qualificada e, mais importante, estruturas institucionais que sejam efetivamente complementares. ${ }^{7}$ Imaginar como os países pobres podem levar a melhor vantagem sobre rendimentos crescentes provenientes de idéias é um desafio.

As implicações institucionais da nova teoria do crescimento são ainda mais desafiadoras. Uma vez que o crescimento é visto como sendo centrado ao redor de idéias, não como um fator exógeno, mas como resultante das ações de agentes econômicos antecipatórios que respondem a incentivos, as instituições deslocam-se para o centro do palco do desenvolvimento. Os arranjos institucionais modelam os incentivos para desenvolver idéias e tornam-se centrais na determinação da taxa de desenvolvimento. Exemplos desse tipo de idéia variam desde o sistema de lançamento de partidas dobradas aos manuais de operação das franquias do MacDonald's, mas as normas administrativas básicas ou as regras legais são, talvez, as mais importantes de todas. Proponentes do novo institucionalismo (p. ex, North, 1981, 1986, 1990) sustentam de forma convincente que a qualidade das idéias incorporadas nesses tipos de instituições é essencial para explicar taxas diferenciais de desenvolvimento. Ao mesmo tempo, North é também explícito na rejeição da idéia de que as formas institucionais as mais eficientes economicamente vão emergir atra-

7 Os efeitos de complementaridade entre trabalhadores qualificados e entre trabalhadores qualificados e o capital ilustram o problema. Trabalhadores qualificados vão querer ir para lugares onde possam obter maiores rendimentos a partir da combinação de suas qualificações com as de outros trabalhadores qualificados. Concentrações de trabalhadores qualificados provavelmente atrairão capital (ver Kremer, 1993; Noorbakhsh e Paloni, 2001; Hoff e Stiglitz, 2001: apêndice A e Easterly, 2001a, p. 150-160). Os países pobres sofrerão triplamente: por terem concentração inicial de trabalhadores qualificados mais baixa, por perderem trabalhadores qualificados para países mais ricos e pelo fato de que seus cidadãos terão menos incentivo para investirem em treinamento do que trabalhadores em países ricos. 
vés de algum tipo de processo funcionalista automático, e sua posição nessa questão é igualmente convincente.

No caso das regras básicas e das instituições de governança que as acompanham, a possibilidade de que idéias desvantajosas para o desenvolvimento a longo prazo sejam "bloqueadas" (Arthur, 1990, 1994) é por demais plausível (Bardhan, 1989, 2001; Pierson, 1997). As instituições dependem de expectativas mutuamente compartilhadas, não só de pessoas envolvidas imediatamente nelas, mas de outras que lidam com elas (cf. Bardhan, 201, p. 276). Qualquer conjunto de expectativas compartilhadas tem uma grande vantagem sobre a incerteza acerca de como a instituição funciona. Esse tipo de "exterioridade de rede" gera rendimentos crescentes e fortes para qualquer forma institucional que consiga se fortalecer por bastante tempo ou de modo suficiente para se tornar a base de expectativas compartilhadas. Uma vez que as instituições se fortaleçam, provavelmente permanecerão, mesmo se tiverem um efeito negativo duradouro sobre o desenvolvimento, obstaculizando a possibilidade de surgimento de instituições mais eficazes (cf. Grief, 1994).

Questões de conflito de distribuição e poder complicam ainda mais o problema. Qualquer conjunto de instituições acarreta uma distribuição de perdas e ganhos. Os "vencedores institucionais" provavelmente ganharão poder político juntamente com benefícios econômicos e, conforme mostra Bardhan (2001, p. 278-79), é provável que não estejam dispostos a apoiar mudanças institucionais que piorem seus ganhos em relação a outros participantes, mesmo se a mudança resultasse em maior produtividade e melhorasse sua posição em termos absolutos. Interesses assumidos quanto aos resultados distributivos de instituições "problemáticas" tornamnas ainda mais difíceis de mudar e ajudam a manter as armadilhas da pobreza firmemente em seu lugar.

O foco sobre idéias e instituições da nova teoria do crescimento faz com que as desvantagens que se apresentam aos países pobres pareçam mais formidáveis do que eram no mundo de Harrod-Domar. Isso é teorica- 
mente tranqüilizador. Encaixa-se no fato lamentável de que a divisão NorteSul persistiu apesar de meio século de "desenvolvimento" e níveis substanciais de industrialização no Sul (ver Arrighi e Silver, 2001). Para os que se interessam em sair da teoria para a prática, porém, isso é desencorajador. Apenas apresentando um conjunto de instituições básicas especificamente adaptadas para superar as armadilhas da pobreza é que as desvantagens cumulativas de ser pobre serão passíveis de serem superadas, mas nossas teorias, talvez até nossas intuições, de como a mudança institucional fundamental ocorre são desastrosamente inadequadas (Hodgson, 1988; Chang e Evans, 2000). Como instituições favoráveis ao desenvolvimento podem ser promovidas onde elas ainda não existem?

\section{Monocultura institucional}

A "virada institucional" na teoria do desenvolvimento deveria ser uma ocasião para novos e criativos pontos de partida tanto nas políticas de desenvolvimento como na teoria. Ao invés disso, a resposta padrão das políticas tem sido a insistência cada vez mais intensiva no que parece ser o equivalente institucional a estratégias antiquadas de monocultura agrícola - o que eu denominaria "monocultura institucional". Organizações internacionais, formadores de políticas locais e consultores particulares se unem para impingirem a presunção de que os países mais avançados já descobriram o melhor planejamento institucional para o desenvolvimento e de que sua aplicabilidade transcende culturas e circunstâncias nacionais. Fazem isso com agressividade cada vez maior através de uma gama de instituições - desde débitos sobre o patrimônio líquido em empresas privadas a relações entre bancos centrais e presidentes dos respectivos países, e à organização de hospitais públicos ou sistemas de pensão.

A monocultura institucional baseia-se tanto na premissa geral de que a eficiência institucional não depende da adaptação ao ambiente sóciocultural local como na premissa mais específica de que versões idealizadas 
de instituições anglo-americanas são instrumentos de desenvolvimento ideais, independentemente do nível de desenvolvimento ou posição na economia global. Formas institucionais correspondentes a uma versão idealizada de supostas instituições anglo-americanas são impostas naqueles domínios organizacionais mais facilmente sujeitos à pressão externa (como organizações formais do setor público). Outras arenas menos acessíveis (como redes de poder informais) são ignoradas, assim como o são as questões de combinação entre as necessidades das instituições modificadas e as capacidades das organizações que as circundam. Na maioria das arenas da vida pública, especialmente aquelas ocupadas com a prestação de serviços públicos, a monocultura institucional oferece a proposta estéril de que a meIhor resposta ao mau governo é menos governo. Seus defensores ficam, então, surpresos quando seus esforços resultam na persistência de uma governança ineficiente, "atomização inaceitável" entre os cidadãos e paralisia política (cf. O ’Donnell, 1993).

A atração da monocultura imposta como um modelo para mudança institucional é compreensível. As instituições básicas de países ricos são, por definição, associadas ao desenvolvimento, ao menos naqueles países. Ter instituições que agentes de países ricos possam entender e nas quais possam trabalhar deveria ajudar os países pobres a se unirem à economia global. Reinventar a roda é, em geral, uma má idéia. Os sistemas de governança deficientes que predominam na maioria dos países do Sul fazem com que a imposição de formas universais pareça uma alternativa superior aos esforços locais para "sobreviver às dificuldades".

Apesar de seus atrativos, entretanto, há várias razões para se duvidar da eficácia da estratégia da monocultura. Na prática, tentativas de imitar instituições de países avançados não são necessariamente o modo mais eficaz de tornar os ambientes locais mais favoráveis aos investidores de países ricos (ver, por exemplo, Pistor, 2000). Impor novas séries de regras formais sem simultaneamente remodelar a distribuição de poder que subjaz 
a arranjos institucionais anteriores é uma estratégia dúbia do ponto de vista de uma política econômica (cf. Hoff e Stiglitz, 2001, p. 418-420). Para Chang (no prelo), a monocultura institucional, no dizer de List, é o mesmo que "dar um chute na escada". Ele afirma que as instituições que atualmente estão sendo impostas no Sul não são, na verdade, aquelas que caracterizaram os países agora desenvolvidos durante o período de sua ascensão e que a imposição dessas instituições tornará o desenvolvimento mais difícil no Sul, não mais fácil. Entretanto outra crítica surge a partir da suposição de que a diversidade institucional tem um valor adaptativo intrínseco para a economia política global como um todo. Se ecologias biologicamente distintas são mais robustas em face de mudanças em seus ambientes e portfolios de investimentos diversificados são superiores face ao risco, então eliminar a diversidade no "portfolio das instituições" do mundo soa como, provavelmente, reduzir a capacidade adaptativa na economia política global. Mesmo que as nações do Sul estejam dispostas a assumir a idéia de que certas propriedades institucionais abstratas - tais como transparência e responsabilidade final - são universalmente valiosas, isso está muito longe da imposição de um conjunto uniforme de estruturas e regras organizacionais específicas que estão implícitas na consideração da monocultura institucional.

De fato, a monocultura não tem funcionado muito bem na prática. Se tivesse, esperaríamos taxas de crescimento aceleradas no Sul durante as últimas duas décadas de esforços intensificados quanto à monocultura institucional. Ao invés disso, os últimos vinte anos testemunharam uma queda nas taxas de crescimento entre os supostos beneficiários desse processo no Sul, tanto absoluta quanto relativamente às taxas de crescimento dos países ricos do Norte. Easterly (2001a, p. 211), por exemplo, acha que, se considerarmos os países do Sul em peso igual, houve uma "desaceleração no aumento de renda per capita de países em desenvolvimento de 2,5\%, de 1960 a 1979, para zero, de 1980-1998". 
Os exemplos concretos mais óbvios da falta de eficácia da monocultura são as "condições" relacionadas à governança impostas pelas Instituições Financeiras Internacionais (IFIs), que geralmente "não são assumidas" e freqüentemente não conseguem produzir os resultados esperados mesmo se adotadas. ${ }^{8}$ Desses exemplos, a Argentina é o mais recente e dramático de falência, enquanto a reestruturação institucional pós-1989 na Rússia seja talvez o mais expressivo de todos. Ao mesmo tempo, os mais famosos em termos de simples crescimento econômico durante os últimos dez anos - p.ex. China, Vietnã e Malásia - exibem padrões institucionais que são embaraçosamente híbridos em relação ao ideal da monocultura.

A incapacidade de produzir crescimento acelerado em rendas reais não é o único problema da monocultura. Modelos anglo-americanos de instituições públicas tendem a negligenciar a distribuição de bens coletivos e a enfatizar a provisão de incentivos individuais sobre resultados distributivos. Se melhorar as instituições públicas de saúde ou corrigir desvios contra os investimentos em escolas primárias dentro de sistemas educacionais são os objetivos, então a superioridade de modelos institucionais anglo-americanos é bastante duvidosa. Resultados insatisfatórios mesmo relativos a aumento de renda, em cuja medida a monocultura deveria ser a mais forte influência, sugerem que avaliações mais amplas de seus resultados seriam ainda mais negativas.

Se a monocultura não é uma boa solução para armadilhas institucionais de baixo equilíbrio, quais estratégias alternativas ou complementares poderiam ser exploradas? Dani Rodrik sugere uma possibilidade. Ele defende (1999a, p. 19) que pode ser "útil pensar em instituiçóes políticas participativas como meta-instituiçóes que provocam e agregam conhecimento local e, por meio disso, ajudam a construir instituições melhores". O "enfoque da capacidade" de Amartya Sen começa de um ponto de partida de análise diferente e percorre um caminho teórico diferente, mas acaba reforçando a proposta de Rodrik.

8 Ver Kapur, 1997, Kapur, 2000; Kapur \& Webb, 2000; Killick, 1995. 


\section{Capacidades, escolha e instituições de desenvolvimento}

O enfoque da capacidade de Amartya Sen reúne uma refinada análise formal dos itens fundadores básicos de utilidade e bem-estar com a análise prática dos problemas da pobreza (principalmente a fome). Alojadas entre o fundamental e o prático estão fortes implicações para os processos de mudança institucional, implicações que são quase a imagem espelhada daquelas oferecidas por monocultores institucionais.

Sen defende que deveríamos avaliar o desenvolvimento em termos da "expansão das 'capacidades' das pessoas para levarem o tipo de vida que valorizam - e têm razão para valorizar", o que é a sua definição de liberdade. ${ }^{9}$ A gama de capacidades é enormemente variada - desde ter acesso fidedigno à nutrição adequada a ter a possibilidade de ser um participante respeitado na vida comunitária. A expansão das capacidades das pessoas depende tanto da eliminação da opressão quanto da provisão de recursos como educação básica, saúde e redes de segurança social, sendo que nenhum desses itens necessariamente se reflete em rendas reais. $\mathrm{O}$ crescimento de rendas muito provavelmente expandirá as capacidades das pessoas, especialmente em níveis mais baixos de renda, mas não pode ser considerado, em si, o padrão de medida decisivo de desenvolvimento ou bem-estar. ${ }^{10}$

A recusa de Sen em aceitar rendas reais como "a melhor coisa" capaz de prover um aval para o desenvolvimento traz a questão da escolha social para o cerne da discussão "sobre o que é desenvolvimento" (cf. Sen, 2001). Primeiro, argumenta que rendas reais são uma métrica analiticamente inadequada para se fazer comparações de bem-estar (1999a, p. 79-80), e que os esforços utilitários para reduzir o bem estar (e portanto os objetivos

9 Dentre a extensa bibliografia de Sen, Development as Freedom (1999a) é talvez a síntese mais acessível.

10 Não é necessário dizer que essa questão não é única para o enfoque da capacidade. Ver, por exemplo, Streeten (1994). Ver também Stewart e Deneulin (no prelo) para uma comparação do enfoque da capacidade com vários outros esforços para "desentronizar o PNB". 
do desenvolvimento) a "algo bom e homogêneo" (rendas reais como um meio de satisfazer preferências subjetivas) são igualmente inadequados. ${ }^{11}$ Assim, segue sustentando que

Existe, conseqüentemente, um forte caso metodológico para se enfatizar a necessidade de determinar critérios explicitamente avaliativos para componentes diferentes de qualidade de vida (ou de bem-estar), e então dispor os critérios escolhidos a um debate público e abrangente e a um escrutínio crítico (1999a, p. 81). ${ }^{12}$

Portanto "não podemos, em geral, considerar preferências como dadas independentemente de debate público" (1999a, p. 153), eis que "um entendimento adequado sobre o que são as necessidades econômicas - seu conteúdo e sua força - requer discussão e intercâmbio" (1999a, p. 153).

Uma vez que preferências e utilidades são vistas como elementos embutidos em um processo de escolha social, o processo de escolha deve ser "democrático", não apenas no sentido "frágil" de se determinar a sucessão da liderança por um processo eleitoral regular, mas no sentido forte do envolvimento contínuo e deliberativo dos cidadãos no estabelecimento de prioridades econômicas. Devemos nos preocupar com as instituições de governança, não apenas porque instituições melhores aprimoram nossa capacidade de alcançar objetivos já estabelecidos pela teoria econômica, mas porque as instituições deliberativas democráticas" fornecem o único meio de se definir adequadamente o que os fins econômicos desejados poderiam ser. Instituições "fortemente democráticas" também oferecem,

\footnotetext{
11 Para uma afirmação pertinente do ponto de vista oposto, ver Srinivasan, 1994.

12 Essas afirmações tomam como premissa o êxito de Sen $(1995,1999 b)$ em desenterrar a economia da aversão de se pensar sobre a escolha social, gerado pelos elegantes teoremas da impossibilidade de Keneth Arrow $(1951,1963)$. Sen argumenta (1999b, p. 354) que "uma completa determinação axiomática de um método particular de se fazer escolha social deve inescapavelmente estar próximo de uma impossibilidade - na verdade apenas quase isso". Modestas contribuições à base informacional sobre a qual escolhas sociais são feitas, por exemplo, mesmo comparações interpessoais parciais de utilidade são suficientes para tornar a escolha social viável. Conforme resume Sen (1999a, p. 279), "o que está em questão não é a possibilidade de escolha social racional, mas o uso de uma base informacional adequada para julgamentos e decisóes sociais".
} 
em si, a oportunidade de exercer uma das mais importantes capacidades humanas, a de fazer escolhas.

Na concepção de Sen (1999a, p. 291), "processos de participação devem ser compreendidos em si como partes constitutivas dos fins do desenvolvimento". A possibilidade de participação em "uma discussão pública e abrangente com troca" não é um adjunto útil à capacidade de se tomar decisões; é parte da definição. ${ }^{13}$ Participar de debates e intercâmbios públicos não é, por sua vez, algo que, por definição, os indivíduos possam fazer sozinhos. Como a linguagem, é uma atividade intrinsecamente coletiva. ${ }^{14}$ Minha capacidade de fazer escolhas depende de minhas expectativas compartilhadas com certo conjunto de companheiros cidadãos sobre como o debate e o intercâmbio públicos podem e devem acontecer. Ou partilhamos dessa capacidade, ou nenhum de nós pode exercê-la. A construção de regras e fóruns organizacionais que geram e recompensam tais expectativas gerais torna-se a tarefa fundamental do desenvolvimento.

Sen não pretende que a construção de instituições de escolha social seja algo fácil, mas recusa-se a utilizar as dificuldades como justificativa para retroceder a um sistema tecnocrata de atribuição de valores. Enquanto observa que (1999a, p. 79) "a busca democrática por concordância ou consenso pode ser extremamente confusa e muitos tecnocratas sentem-se suficientemente contrariados com essa confusão, a ponto de ansiar por alguma fórmula maravilhosa que simplesmente Ihes daria valores prontos, que são 'simplesmente corretos", mantém-se firme em sua convicção de que atalhos tecnocráticos devem ser rejeitados, pois " a questão de atribuir valores referese à avaliação e julgamento, e não a alguma tecnologia impessoal”.

A crítica de Sen sobre a volta às decisões tecnocráticas também fornece um modo de se pensar sobre por que a "monocultura" institucional pode ser ineficaz. As "más políticas" e o "mau governo" que a comunidade do desenvolvimento internacional gostariam de "reformar" no Sul são

13 Os paralelos entre as prescrições relativas ao desenvolvimento de Sen e as preocupações de Jurgen Habermas com a "ação comunicativa" em sociedades industriais avançadas são marcantes. Ver Habermas (1962, 1989, 1991).

14 Ver Taylor (1995) para uma discussão análoga acerca dos "bens irredutivelmente sociais". 
sintomas de que uma capacidade subjacente para se fazer escolhas sociais está ausente. A imposição externa de planejamentos uniformes tenta lograr a função mais fundamental de desenvolver instituições que permitam escoIhas sociais efetivas. Apropriando-se de escolhas sociais antes que os mecanismos para realizá-las tenham sido desenvolvidos, a monocultura reduz os estímulos para que estados e cidadãos dediquem sua atenção à construção de instituições para a tomada de decisões, e, portanto, reduz a probabilidade de que tais instituições possam de fato emergir.

Embora situe a deliberação no centro do desenvolvimento, Sen não analisa como "debates e intercâmbios públicos" eficazes, em termos de desenvolvimento, poderiam ser instalados em instituições fortalecidas. Endossa com firmeza o valor das eleições e dos direitos civis (mais especificamente contra os que defendem ser os "valores asiáticos" legitimadores da norma autoritária), mas também admite que a existência de eleições e direitos civis apenas reforçará a procura por capacidades desenvolvidas até então. ${ }^{15}$ Deixa-nos, assim, com um desafio. Como poderiam as instituições "fortemente democráticas" emergir? A que elas se assemelhariam se de fato emergissem? Quais seriam as conseqüências da mudança de governança para uma orientação deliberativa, considerando a realização de outros objetivos relativos ao desenvolvimento?

\section{Deliberação e desenvolvimento}

Os esforços mais interessantes para colocar os "debates e intercâmbios públicos" diretamente em processo de governança podem ser livremente rotulados como "democracia deliberativa". ${ }^{16} \mathrm{O}$ conceito de "demo-

\footnotetext{
15 De um lado, há a famosa proposta de Sen de que nenhuma democracia independente jamais experimentou a fome (1999a, p. 178-180). De outro, mostra (1999a, p. 154), por exemplo, que, enquanto disputas eleitorais e os direitos civis foram suficientes para proteger a Índia da fome, não forneceram a base para lidar com a negação ostensiva e penetrante das capacidades na forma de subnutrição regular e analfabetismo persistente.

16 Para discussões sobre como a "democracia deliberativa" poderia funcionar, ver Benhabib, 1996; Bonham \& Rehg, 1997; Elster, 1998; Gutman \& Thompson, 1996; Mansbridge, 1990; Fund e Wright, no prelo.
} 
cracia deliberativa" ou, conforme Fung e Wright (no prelo, p. 20) o denominam, "governança fortalecida pela participação", refere-se a um processo de "planejamento, solução de problemas e estratégia conjuntas" envolvendo cidadãos comuns, em que "estratégias e soluções serão articuladas e forjadas através de deliberação e planejamento com outros participantes", de tal modo que "os participantes freqüentemente formarão ou transformarão suas preferências à luz dessa realização", assim permitindo soluções que teriam sido impossíveis, se consideradas as preferências iniciais. Se fosse possível implantar esse tipo de processo deliberativo em unidades políticas suficientemente amplas para se ter um impacto sobre trajetórias de desenvolvimento - ou seja, em nível provincial ou municipal - teríamos algo que poderia ser chamado "desenvolvimento deliberativo". Esforços para explorar o "desenvolvimento deliberativo" assentam-se sobre a experiência existente com democracia eleitoral "frágil" e experimentos de pequena escala em "participação".

A era em que a democracia eleitoral poderia ser vendida como uma panacéia do desenvolvimento há muito já passou, caso tenha sequer existido. ${ }^{17}$ Já que as transferências de poder por eleições tornaram-se a norma em um conjunto cada vez mais amplo de países, tornou-se cada vez mais claro que promover eleições regulares e manter pelo menos proteção nominal para os direitos civis não é suficiente para gerar debate público que tenha verdadeira relação com a consideração de objetivos de desenvolvimento ou a alocação de recursos coletivos. Esse é o problema da democracia "esvaziada" (hollowed out) (Yusef e Stiglitz, 2001:249), que foi sinalizado no início deste artigo. Com a participação nas eleições em queda e custosos programas televisivos tornando-se a principal base de informação para as decisões eleitorais, o processo eleitoral está mais próximo de refle-

17 A literatura sobre democracia e desenvolvimento é, naturalmente, por demais vasta para se tentar tratar dela aqui. Dentre muitos outros, ver Rueshemeyer, Stephens e Sephens (1992) para uma análise histórica das condições sociais e econômicas levando à democratização; Przeworski, et al. (2000) para uma análise das causas e efeitos da democracia no mundo pós Segunda Guerra Mundial; e Landa e Kapstein (2001) para a revisão recente do debate. 
tir a base superficial de informações associada com a impossibilidade arroviana (v. nota 12) do que o tipo de "exercício de escolha social" que Sen defende.

Apesar disso tudo, a difusão global de normas eleitorais é uma tendência encorajadora do ponto de vista do desenvolvimento deliberativo. As eleições democráticas e os direitos civis continuam sendo os pré-requisitos fundamentais para o florescimento de processos deliberativos "mais fortes". À medida que a democracia "frágil" se torna cada vez mais universal, torna-se mais plausível pensar em tentativas de institucionalizar algo mais próximo a autênticos exercícios de escolha social.

Estudos de participação em nível de projetos e comunidades são, também, encorajadores. ${ }^{18}$ Já que a conexão entre instituições deliberativas e resultados econômicos é extremamente difícil de se analisar em níveis maiores de agregação, a evidência positiva em uma escala menor é uma expressão de crescente confiança em que uma experimentação mais ampla vale a pena. Trabalhos recentes sobre os efeitos da participação na eficácia de projetos de Bancos Mundiais é um bom exemplo. ${ }^{19}$ Parece haver um consenso cada vez maior no Banco de que a participação tem sentido instrumental. De acordo com Kanbur e Squire (2001, p. 215), "Os profissionais liberais que professam teses desenvolvimentistas chegaram a um consenso de que a participação por parte dos beneficiários envolvidos melhora o desempenho de um projeto". Mesmo no nível mais agregado de desempenho de empréstimos, "o 'sentido de propriedade' mostrou ser o fator-chave no sucesso ou insucesso de empréstimos de ajuste estrutural" (Ibid.). ${ }^{20}$

\footnotetext{
18 P. ex., Uphoff et al. (1979); Uphoff, (1986, 1992); Ostrom, 1990, 1995. É também, aqui, relevante o trabalho sobre associações secundárias (e.g. Cohen e Rogers, 1995) e capital social (e.g. Evans, 1996; Putnan, 1993, 2000; Woolcock, 1997) e mobilização social (e.g. MacAdam, Tarrow e Tilly, 2001). A recente coletânea de Houtzager e Moore (no prelo) sobre "as políticas de inclusão" é particularmente interessante.

19 O trabalho de Deppa Narayan $(1994,1997,2000)$ é um dos mais instigantes.

20 Ver também Branson e Jayarajah (1995).
} 
As implicações dessa mudança não devem ser superestimadas. "Participação" em projetos e "propriedade" de empréstimos envolve possibilidades limitadas para o exercício da escolha, certamente não do tipo de exercício de avaliação social amplamente desenvolvido que Sen advoga. A participação em nível de comunidades, ao contrário da participação em nível de projetos, permite um escopo mais amplo, mas a questão de quanto o "fortalecimento" real é gerado permanece não respondida (cf. Houtzager e Moore, no prelo). Nem essas versões amenas de tomada de decisão encontram necessariamente receptividade entre os estrategistas de políticas globais. A rejeição da versão rascunhada do Relatório do Desenvolvimento Mundia/de 2000-2001, em parte com base na idéia de que tenha sublinhado excessivamente a idéia de fortalecimento de poder, é um bom caso em questão (Wade, 2001a, 2001b).

A hegemonia global incontestável da democracia eleitoral e o corpo crescente de evidências de que outras formas de participação são eficazes em termos de desenvolvimento se combinam para criar um ambiente político no qual o desenvolvimento deliberativo não aparece como uma proposta de todo fantasiosa. Não obstante, para que a democracia deliberativa seja atraente enquanto estratégia de desenvolvimento, três coisas deveriam ser verdadeiras. Primeiro, as instituições deliberativas devem ser "socialmente auto-sustentáveis" no sentido de que os cidadãos comuns estão dispostos a investir seu próprio tempo e energia em oportunidades de tomada de decisão que tais instituições oferecem e fornecer apoio eleitoral para os partidos e os líderes políticos que os defendem. Segundo, as instituições deliberativas devem, sob algum conjunto de condições empiricamente plausíveis, ser capazes de superar o "problema da economia política", o que significa dizer a oposição dos poderosos, que têm interesses manifestos nas estruturas existentes de tomada de decisão. Por fim, processos deliberativos não devem prejudicar o exercício de habilidades que dependem de recursos materiais. Mais especificamente, não de- 
vem ser tão ineficientes economicamente ou inclinados em direção à redistribuição, que reduzam o crescimento de renda real a um ponto que exceda seus benefícios intrínsecos.

Se as respostas tanto para a questão da sustentabilidade social quanto para o problema da economia política são negativas, então as estratégias deliberativas são inexeqüíveis - pura ilusão. Se a resposta para o "problema do crescimento" for negativa, então as instituições deliberativas possivelmente não serão atraentes, mesmo para aqueles que valorizem suas propriedades intrínsecas. Nenhuma dessas questões pode ser respondida a priori, mas a que foi mais completamente considerada na literatura tradicional sobre desenvolvimento é, sem surpresa, a do problema do crescimento.

Não há lógica teórica clara para prever os efeitos da democracia deliberativa baseada, de modo geral, no crescimento. Discussões abertas e intercâmbio público poderiam promover crescimento pela fiscalização de dirigentes predatórios cujas políticas, de outra forma, subverteriam incentivos para investimento. Velhas discussões de que as estratégias de redistribuição constituem riscos porque os ricos economizam mais e os quocientes de poupança são a chave para o crescimento são menos plausíveis do que já o foram nos dias de Harrod-Domar. Uma série de trabaIhos empíricos recentes sugerindo que as estratégias de redistribuição podem ter um efeito positivo no crescimento da renda real solapam a idéia de que a redistribuição é prejudicial para o crescimento.

Stewart (2000, p. 5) observa uma vasta gama de estudos empíricos recentes mostrando "que países com distribuições de renda mais iguais apresentam maior crescimento". ${ }^{21}$ Enquanto a relação total ainda permanece contestada (e.g. Fishlow, 1995; Li \& Zou, 1998; Landa \& Kapstein, 2001), o debate produziu apoio para argumentos que conectam políticas

21 Esses estudos recentes se constroem, é claro, em uma longa tradição de trabalho remontando pelo menos a Adelman e Morris (1973), Chenery, Ahluwalia, et al. (1979), e Streeten et al. (1981). 
igualitárias com crescimento, o que é bastante consistente com o enfoque da capacidade. Maior igualdade é associada a maiores níveis gerais de saúde, nutrição e educação que, por sua vez, promovem uma população mais produtiva. Da mesma forma, uma distribuição mais igualitária de ativos (terra e crédito sendo os exemplos arquetípicos) ${ }^{22}$ oportuniza contribuintes produtivos, dentre pessoas que antes não eram capazes de utilizar sua energia e idéias porque lhes faltavam os insumos complementares.

Os argumentos de que as estratégias igualitárias podem aumentar o crescimento são pelo menos tão convincentes quanto os argumentos de que podem depreciá-lo. Se lançarmos a suposição conservadora de que os regimes deliberativos são "neutros em termos de crescimento", ${ }^{23}$ então a inferência a partir da análise das conseqüências econômicas da democracia eleitoral sugere que seus efeitos econômicos convencionais provavelmente serão positivos no todo. Rodrik (1999a, 1999b), por exemplo, defende que a democracia, conquanto não aumenta as taxas globais de crescimento, realmente aumenta a qualidade do crescimento. Ele conclui (1999a, p. 33) que "Regimes mais participativos produzem maior igualdade (...) sem custo para o crescimento econômico ao mesmo tempo em que produzem maior estabilidade e capacidade de recuperação em geral".

Mesmo que não sejam prejudiciais ao crescimento, as instituições deliberativas podem ainda ser inatingíveis. Versões funcionalistas do institucionalismo que assumem uma evolução fácil em direção às formas institucionais "mais adequadas" têm particularmente pouca probabilidade de incorporar a noção de instituições deliberativas. ${ }^{24}$ Mesmo que a deliberação pública funcione, e os detentores do poder e do privilégio se beneficiem, juntamente com o resto da comunidade, de uma governança aprimorada em termos de maior estabilidade política ou custos mais baixos de

22 Sobre o caso específico de distribuição de terra, ver, por exemplo, Lipton (1993), Deininger e Squire (1998), Ravallion (1998). 23 A suposição da "neutralidade total" é consistente com as avaliações de Przeworski e Limongi (1993) e Przeworski et al. (2000) de que ter sucessão eleitoral regular em regime político é fator neutro no que tange ao crescimento.

24 Novamente, ver Pierson, 1997 e especialmente Bardhan, 2001. 
aplicabilidade de leis e regulamentos, o poder reduzido é um resultado quase definitório para elites privadas e políticos. A isso, certamente reagirão pertinentemente. Como mostra Sen, os tecnocratas podem sentir-se igualmente ameaçados. Planejamentos impostos aumentam seu poder e prestígio; atribuir importância maior às deliberações de pessoas comuns Ihes será, provavelmente, frustrante, se não aviltante.

A hipótese mais plausível é a de que as instituições deliberativas podem ser bastante desejáveis, tanto devido ao seu impacto intrínseco sobre as capacidades quanto devido aos seus efeitos econômicos globais. A exeqüibilidade política é mais duvidosa. O que é mais óbvio é a necessidade de maior experimentação. Nem os retornos do desenvolvimento deliberativo nem sua exeqüibilidade podem ser efetivamente avaliados abstratamente. Felizmente, existem alguns poucos experimentos relativamente duráveis. Examinar dois deles é provavelmente a melhor maneira de se refinar os argumentos teóricos.

\section{Desenvolvimento deliberativo na prática: dois exemplos}

Para explorar mais os mecanismos e conseqüências do desenvolvimento deliberativo, utilizarei os dois exemplos que são analisados em Fung e Wright (no prelo). O processo de "orçamento participativo" iniciado pela cidade de Porto Alegre, no Brasil, tornou-se um exemplo amplamente citado de "democracia deliberativa" em nível municipal. O caso ainda mais bem conhecido do Kerala, na Índia, fornece outro exemplo no nível subnacional, nesse caso um estado de cerca de 30 milhões de pessoas. Juntos, oferecem uma oportunidade de se ver como os conceitos abstratos do debate e do intercâmbio públicos podem ser traduzidos em realidades institucionais concretas.

O processo do "Orçamento Participativo" (OP) de Porto Alegre foi concebido por uma nova administração municipal em 1989 para melho- 
rar os sistemas corruptos e clientelísticos de alocação de recursos públicos que prevaleciam nessa cidade, bem como na maioria das cidades brasileiras. ${ }^{25}$ Envolvendo os cidadãos, especialmente aqueles mais privados dos serviços públicos, na alocação de investimentos na infra-estrutura pública, esperava-se produzir uma distribuição de investimentos públicos tanto mais eficiente quanto mais eqüitativa. O sistema requer investimento substancial do tempo dos cidadãos em um ciclo anual de deliberações, começando com assembléias em cada uma das dezesseis regiões da cidade que debatem os resultados dos anos anteriores e elegem delegados que se encontram semanal ou quinzenalmente. Esses, por sua vez, preparam-se para um segundo conjunto de assembléias regionais que decidem sobre as prioridades dos anos seguintes e também elegem um número menor de delegados para o "Conselho Municipal do Orçamento Participativo". Esses últimos delegados irão se encontrar, quinzenalmente, com representantes da administração municipal para finalizarem o orçamento (Baiocchi, no prelo, p. 52-54).

Embora definitivamente "confuso", o sistema parece funcionar. Seu sucesso no alcance da sustentabilidade social é impressionante. Longe de diminuir com o tempo, a participação no processo orçamentário se expandiu. Aumentos dramáticos nos primeiros poucos anos das operações do programa foram seguidos por aumentos mais graduais nos últimos anos. Baiocchi (no prelo, p. 63) observa que, como resultado de sua participação, os cidadãos comuns não só "adquirem competências específicas relacionadas ao orçamento, mas também adquirem habilidades no debate e na mobilização de recursos para objetivos coletivos". Além disso, o ambiente político mais participativo parece ter levado as pessoas a perceberem outros tipos de ação coletiva. De acordo com Baiocchi, o número de associações vizinhas triplicou desde que o programa começou e o número de

25 O debate que segue foi extraído principalmente de Baiocchi (no prelo). Ver também Abers (no prelo), Baiocchi (2001), Baierle (2001), Pozzobono (1998), Santos (1998), Fedozzi (1997), Genro \& Souza (1997). 
cooperativas de moradia quintuplicou. O Orçamento Participativo também provou ser politicamente carismático em termos eleitorais. O Partido dos Trabalhadores, que iniciou as reformas, não só conquistou inauditos quatro mandatos no governo municipal, mas a bandeira do "orçamento participativo" tem sido erguida por outras municipalidades e em nível estatal (Schneider e Goldfrank, 2001).

O experimento de Porto Alegre também confirma alguns dos esperados efeitos econômicos do desenvolvimento deliberativo. Um controle popular mais eficaz da alocação das despesas públicas realmente parece levar a um maior disposição dos cidadãos de investir em bens coletivos. Em administrações municipais anteriores, despesas com pessoal absorviam quase todo o orçamento; apenas $2 \%$ eram disponíveis para investimentos. Após cinco anos do sistema deliberativo, um pequeno aumento inicial nos impostos associado a uma maior eficiência permitiram que a porcentagem subisse para 20\% (Baiocchi, no prelo, p. 55-56). Conseqüentemente, a infra-estrutura pública essencial cresceu muito. Durante uma década de operação do sistema, a cobertura de esgotos dobrou de menos da metade dos domicílios para 98\%, o acesso à água potável cresceu de $75 \%$ a $98 \%$; o número de escolas cresceu duas vezes e meia. O sistema de transporte coletivo da cidade conquistou prêmios por sua eficiência. Embora Porto Alegre não possa oferecer taxas de crescimento muito maiores do que as do resto do Brasil, parece mesmo ter crescido em uma taxa comparável, confirmando a hipótese básica de serviços em alta, neutra em termos de crescimento.

O estado de Kerala, na Índia, apresenta uma dinâmica análoga em maior escala e em maior período de tempo. ${ }^{26}$ Uma história épica de mobilização popular para assegurar reforma agrária, desde os anos 1930 até 1970, competições incansáveis entre partidos políticos, altos níveis de organização sindical e organizações de sociedade civil complementares

26 Há uma vasta literatura sobre o caso Kerala, incluindo, entre muitas outras fontes, Franke e Chasin, 1989; Heller, 1999; Isaac, Thomas TM e Richard Franke, 2000; Isaac, Thomas TM e Patrick Heller, no prelo. 
levam observadores contemporâneos a se surpreenderem com a "absoluta densidade das organizações civis e o vigor da vida associativa" (Heller, 2000, p. 497). Mais recentemente, Kerala iniciou uma "Campanha para a Descentralização Democrática", que deslocou o controle de distribuição sobre $40 \%$ do orçamento público do estado para conselhos de aldeias (Panchayats). Essa última realização é ainda mais impressionante porque claramente não constava dos interesses definidos tanto por burocratas do estado quanto pelos sindicatos do setor público que formam a base mais importante do partido político acelerador das mudanças (Isaac, 2000, Isaac e Heller, 2001). A descentralização democrática privou esses grupos corporativistas de importantes fontes de poder e patronato, sugerindo que o "problema da economia política" nem sempre é intransponível.

A longa tradição em Kerala de intenso engajamento popular nas tomadas de decisões políticas também proporcionou frutos desenvolvimentistas, resultando em um nível de desenvolvimento humano comparável ao de estados-nações com várias vezes seu nível de renda per capita. Os níveis de alfabetização são superiores a 90\% em Kerala, ao contrário dos 50\% para o resto da Índia. Em 1995, a taxa de mortalidade infantil em Kerala era inferior à dos outros estados indianos, aproximando-se da taxa da Coréia do Sul, que possuía trinta vezes o seu nível de renda per capita, representando um terço da do Brasil, que tinha dez vezes a sua renda per capita (Heller, 1999, p. 8). Sen (1999a, p. 22-23) observa que, se considerarmos a capacidade mais fundamental o fato de estar vivo, então os cidadãos de Kerala estão em melhor condição do que os afro-americanos que vivem nos Estados Unidos, já que as expectativas de vida do povo de Kerala são maiores. Todas essas realizações dependem de uma prestação de serviços públicos bastante eficiente, como educação e serviços de saúde básicos, a qual, por sua vez, está enraizada em um extraordinário nível de envolvimento popular no processo de governança. 
Alguns críticos (e.g. Tharamangalam, 1998) têm afirmado que, a despeito dessas realizações, Kerala ainda demonstra os efeitos anticrescimento devidos à participação popular intensa. É, de fato, verdade que, do fim dos anos setenta ao início dos oitenta, os quocientes de crescimento de Kerala perderam terreno para os do resto da Índia (que não eram nada espetaculares nesse período). O desempenho do crescimento de Kerala após 1985, entretanto, tem se mantido alinhado com o ritmo bastante respeitável da Índia como um todo. No período de 1985-1993, por exemplo, o produto da manufatura cresceu em 5,9\% em Kerala e 5,5\% na Índia como um todo (Heller, 1999, p. 211). Da mesma forma, os níveis globais de investimento em Kerala no fim dos anos noventa eram um pouco mais elevados do que a média indiana (Heller, 1999, p. 233). Assim, resultados mais recentes deslocam Kerala para a categoria "neutro em termos de crescimento".

Quais são as implicações desses casos para os três tipos de questões que foram antes levantadas como centrais para uma avaliação global do desenvolvimento deliberativo? Sua evidência é mais bem definida no que tange à questão da sustentabilidade social, mas elas também trazem luzes interessantes para o "problema da economia política" e o "problema do crescimento". Ao mesmo tempo, ajudam a esclarecer o caráter político e organizacional das instituições deliberativas.

A resposta à questão "será que as não-elites se tornarão suficientemente engajadas de modo a fazer com que o modelo deliberativo funcione?" é claramente positiva. Esses casos mostram que, a despeito de investimentos maiores na exigência de tempo e de energia dos cidadãos, os sistemas deliberativos não são necessariamente abalados pela mesma apatia que infecta a democracia frágil. Quando os sistemas de deliberação são vistos como, de fato, modeladores de resultados concretos, os cidadãos comuns toleram sua "confusão", e investem o tempo e a energia necessários para fazê-los funcionar. Em vez de fazerem a escolha "racional" de que seu input individual terá pouco impacto no produto final e, portanto, não 
garantirá o custo do tempo perdido, os cidadãos comuns parecem concordar com Sen em que a capacidade de fazer escolhas é uma modalidade do funcionamento humano ${ }^{27}$ intrinsecamente valiosa e recompensadora.

Ao mesmo tempo em que fornecem evidência sobre a "questão da sustentabilidade social", esses casos também tornam claro o fato de que a efetiva participação social requer um contexto sólido de instituições formais. Confirmam a proposta de Houtzager e Moore (no prelo) de que as "ações descoordenadas e descentralizadas da sociedade civil" são insuficientes para a emergência ou sustentação de instituições deliberativas. Os aparatos organizacionais formais - administrações de estado e partidos políticos - desempenham papéis centrais em ambos os casos.

Um aparato administrativo público, com capacidade necessária para fornecer inputs informacionais e implementar as decisões que resultam desse processo, é um elemento central para possibilitar a deliberação (ver também Heller, 2001; Evans, 1995, 1996).28

De modo contrário, uma das mais importantes conseqüências das instituições deliberativas é "suspender" as barreiras quanto à transparência e à responsabilidade final do aparato estatal. Dada a extensão que a questão da corrupção assume no Sul, como problema intratável, essa é uma questão particularmente valiosa do processo deliberativo. ${ }^{29}$

Os efeitos de instituições deliberativas na eficiência da administração pública são obviamente relacionados ao seu impacto no fornecimento de bens coletivos. Os processo deliberativos dão aos cidadãos acesso a um

\footnotetext{
27 Esses experimentos também corroboram a proposição otimista de Hirschman (1981, p. 85-91) de que os próprios exercícios envolvidos na participação pública podem ser em si mesmos satisfatórios.

28 Nos termos de Fung e Wright (no prelo, p. 25), cada um dos casos analisados "atrela o poder e os recursos do estado à deliberação e à participação popular".

29 Assim como ajudam a lidar com a corrupção, as instituições deliberativas podem canalizar o conflito de maneira a evitar o tipo de violência econômica e politicamente debilitante que infecta grande parcela do Sul. Conflitos de sindicatos e partidos em Kerala ocasionalmente descambam para a violência física, mas o estado escapou da violência pública que infecta cronicamente outras partes da Índia, como o tipo de violência de classe anárquica, que mina a possibilidade de governança efetiva em outros estados indianos como Bihar, e o conflito armado que surge ainda em outros estados (Heller, 1999; 2000, p. 500). Como Kerala, Porto Alegre é caracterizada por intenso conflito político, mas não o tipo de violência anárquica que é endêmica em áreas rurais e até mesmo se espalhou para o sudeste urbano (p.ex., os recentes assassinatos de líderes municipais em Campinas e Santo André).
} 
conjunto expandido de informações acerca da alocação dos recursos públicos. A participação nas decisões sobre a alocação também dá aos cidadãos um interesse mais claro em monitorar as implementações dessas decisões. Uma capacidade ampliada de monitorar a alocação e os resultados das despesas públicas é o outro lado da moeda na disposição de fazer investimentos maiores em bens públicos. Os dois aspectos combinados mitigam a suboferta de bens coletivos que, é um obstáculo-chave crescente para a melhor qualidade de vida nos países do Sul.

A institucionalização dos processos deliberativos está também intimamente ligada à dinâmica da competição entre partidos. Tanto em Kerala como em Porto Alegre, o impulso em direção aos processos deliberativos foi acionado por partidos combativos de esquerda, com ideologias marxistas, possibilitados (e forçados) por um contexto nacional mais amplo de competição eleitoral e direitos civis a estabelecer seu foco sobre estratégias mobilizadoras. Engajar suas bases em um projeto positivo de governança fazia sentido para esses partidos como uma estratégia política. Sem esse ímpeto, é improvável que tais experimentos deliberativos tivessem vingado.

Observar a relação entre a dinâmica política e as instituições deliberativas ajuda a esclarecer o "problema da economia política" criado pela probabilidade de oposição da elite. Esses casos sugerem que um grupo seleto de elites políticas pode ter um interesse forte e positivo em instituições deliberativas. Elites cujo "capital político" toma a forma de habilidades mobilizadoras e cujos eleitores são os pobres e a classe média podem achar a construção de instituições deliberativas um projeto muito atraente. O poder perdido devido ao escopo reduzido no uso de obras públicas como recompensas clientelísticas provavelmente será mais do que compensado pelo poder e a legitimidade conquistados através da capacidade aumentada de distribuição de bens públicos em geral e o comprometimento aumentado de eleitores no processo político. Essa lógica subjaz, mais uma vez, à importância de regras eleitorais firmemente aplicadas e 
de liberdades civis para a construção de instituições deliberativas. Um "campo de possibilidades eleitorais" que maximiza os ganhos da mobilização pacífica oferece fortes incentivos às elites políticas para explorarem opções deliberativas.

As elites administrativas são, também, apoiadores potenciais. A informação mais precisa sobre onde estão as verdadeiras necessidades e a oferta de um controle mais eficiente da alocação e da distribuição de bens públicos deveriam melhorar o desempenho, a legitimidade e até a disposição administrativa de investir no próprio aparato administrativo. Isso, por sua vez, oferece uma recompensa administradores competentes pela circunscrição de seu privilégio tecnocrático. O problema das elites privadas e dos partidos que as representam permanece, ${ }^{30}$ mas, mesmo aqui, a oposição não deve ser uniforme. Aqueles que têm uma perspectiva consolidada que valoriza o potencial desenvolvimentista da boa governança e do investimento em bens públicos podem ser persuadidos. O obstáculo central está nos pressupostos ideológicos convencionais dos opositores sobre a "irracionalidade econômica" dos resultados deliberativos.

Tudo isso tem implicações para o "problema do crescimento". Uma distribuição de serviços vitais básicos - educação, saúde, infra-estrutura pública - ampla e mais eficiente é algo bom para o crescimento a longo prazo. Reduções na corrupção e na violência também devem ajudar. Objetivamente, as instituições deliberativas produzem muitas das características comumente associadas com o "bom clima de investimento". A questão é se a hostilidade ideológica das elites privadas reduzirão os investimentos produtivos locais a um ponto que contrabalance os efeitos positivos de uma governança com melhor infra-estrutura. ${ }^{31}$ Examinando esses

30 A análise comparativa de Goldfrank (2001) de casos mais ou menos bem sucedidos de deliberação em nível municipal também sugere que líderes de partidos não associados com o desenvolvimento deliberativo podem estar entre seus oponentes mais implacáveis e eficientes.

31 Heller (1999, p. 234-35) observa que, em 1997, uma das grandes revistas de negócios da Índia classificou Kerala entre os melhores $15 \%$ de todos os estados indianos em termos de "vinte e oito medidas objetivas de infraestrutura física e social, mãode-obra, governo, e incentivos fiscais". Na mesma pesquisa, a avaliação subjetiva de investidores potenciais classificou o Kerala entre os últimos $15 \%$. 
casos, a melhor hipótese continua a ser a de que o desenvolvimento deliberativo, como a democracia frágil, é "neutro em termos de crescimento".

Se a hipótese de "neutro em termos de crescimento" é correta, os detratores do desenvolvimento deliberativo sempre serão capazes de apontar regimes autoritários que crescem mais rápido do que os deliberativos, e de argumentar que o aumento das capacidades possibilitado pelo sucesso material desses regimes pode compensar oportunidades perdidas no exercício da escolha. Essa análise, é claro, não considera o fato básico de que é responsabilidade dos cidadãos desses países decidir quais capacidades eles mais valorizam. Também não percebe outra questão básica. Nem as democracias frágeis nem os regimes autoritários garantem um crescimento maior da nação. Os dados de Easterly (2001a, p. 211) de 1980-1998 até sugerem que a "expectativa racional" para um país qualquer no Sul é de crescimento zero. Sob essas circunstâncias, a opção de instituições deliberativas "neutras em termos de crescimento", que criam a possibilidade de exercer escolha e oferecem distribuição mais eficaz de bens coletivos, é interessante.

O que os exemplos concretos de Kerala e de Porto Alegre demonstram é que o desenvolvimento deliberativo não é apenas um imperativo teórico e filosófico, conforme sugere o trabalho de Sen, mas também uma possibilidade real.

\section{Além da Monocultura Institucional}

Explorar as possibilidades do desenvolvimento deliberativo é apenas uma parcela do esforço geral de se tirar vantagem das novas idéias teóricas que invadiram a teoria do desenvolvimento no decorrer dos últimos 25 anos. A nova teoria do desenvolvimento, especialmente se lida conjuntamente com o novo institucionalismo do Norte, fornece boas razões para se 
acreditar que instituições básicas de governança desempenham um papel essencial no fomento ao desenvolvimento. Sem propostas mais imaginativas para a melhoria de qualidade das instituições fundamentais de governança, o desapontamento provavelmente continuará. O enfoque da capacidade de Sen impele-nos na direção da proposta do desenvolvimento deliberativo. A expansão analítica dos objetivos de desenvolvimento próprios do enfoque da capacidade torna as instituições deliberativas tanto um meio inevitável na orientação de esforços desenvolvimentistas como um bem intrínseco fundamental em si mesmas.

Alguns podem se preocupar com o fato de que a busca de uma teoria mais abrangente vá minar as políticas básicas projetadas para sustentar investimentos em bens produtivos, mas há pouco perigo disso. A inércia intelectual e o persistente poder das elites com interesse direto em políticas que protejam rendimentos para o capital assegurarão atenção voltada para o investimento. De fato, as dificuldades intelectuais da tradução das complexidades da análise institucional em sugestões concretas para a política do desenvolvimento e sua prática são suficientemente desanimadoras para que o retorno a modelos mais simples seja uma tentação constante.

Estratégias institucionais muito simplificadas são um problema mais provável do que a negligência do papel do investimento. A "monocultura institucional" não tem apenas poucas possibilidades de resolver problemas locais de governança; também tem possibilidades de tornar os empréstimos financeiros menos eficazes. Mesmo as IFIs admitiram que tentar impor modelos de planejamentos importados sem se preocupar com o sentido de "propriedade" local é quixotesco. Incorporar o processo de empréstimo institucional em uma matriz global de desenvolvimento deliberativo deve levar a um sistema de empréstimo mais cuidadosamente selecionado e a menor desperdício de recursos em transferências fracassadas. Privilegiar o desenvolvimento de capacidades locais para realizar escolhas torna a relação entre escolhas locais e planejamentos globais mais complexa, mas 
também realiza ganhos de um crescente sentido de "propriedade local", melhor exploração do conhecimento local e melhor ajuste com instituições locais existentes.

O desenvolvimento deliberativo é apenas uma maneira de se ir além da monocultura institucional, mas é uma maneira promissora. Nossos dois casos empíricos reforçam outros argumentos teóricos ao sugerirem que as estratégias deliberativas são intrinsecamente satisfatórias para os cidadãos que delas participam enquanto melhoram a governança e aumentam a oferta de bens coletivos. Dados seus outros benefícios, o desenvolvimento deliberativo deveria ser considerado uma alternativa atraente contanto que não produzisse crescimento de renda real significativamente pior do que o esperado a partir das estratégias convencionais. Como os níveis médios de crescimento de renda real esperados no Sul diminuem, a hipótese de que o desenvolvimento deliberativo será pelo menos neutro em termos de crescimento, em comparação com outras estratégias, é ainda mais plausível e se torna uma alternativa cada vez mais atraente.

Nada disso deve nos tentar a representar o desenvolvimento deliberativo como uma panacéia. Seria um erro profundamente irônico cair na armadilha da monocultura e tentar impor o desenvolvimento deliberativo como alternativa de planejamento. Embora o exame cuidadoso das possibilidades de empréstimo de idéias seja uma boa sugestão nesse domínio, bem como em outros, o desenvolvimento deliberativo só tem alguma chance de êxito quando emerge da dinâmica de políticas locais. Os argumentos aqui expostos podem facilitar a consideração local das estratégias deliberativas em duas maneiras. Primeiro, os agentes locais interessados em adotar o desenvolvimento deliberativo podem ter menos possibilidades de serem perturbados pelas asserções em que as teorias econômicas do desenvolvimento enfatizam as conseqüências antidesenvolvimentistas das instituições deliberativas quando, de fato, o oposto é a verdade. Segundo, quando o "sistema do desenvolvimento" 
Sociologias, Porto Alegre, ano 5, no 9, jan/jun 2003, p. 20-63

propicia a reflexão sobre a conclusão de William Easterly (2001b) de que " $O$ melhor que a comunidade de auxílio estrangeiro pode fazer é apoiar a mudança genuína naquelas ocasióes preciosas em que isso ocorre", é mais provável que se considerem exemplos de desenvolvimento deliberativo como "ocasióes preciosas de mudança genuína".

\section{Referências}

ABERS, Rebecca. Inventing Democracy. Boulder: Lynne Reiner (no prelo).

ADELMAN, Irma. MORRIS, Cynthia Taft. Economic growth and social equity in developing countries. Stanford, CA: Stanford University Press, 1973.

AGHION, P. \& HOWITT, P. Endogenous Growth Theory. Cambridge, MA: MIT Press, 1999.

ARRIGHI, Giovanni \& SILVER, Beverly. Industrial convergence, globalization, and the persistence of the North-South divide. Trabalho apresentado nos encontros da Associação Sociológica Americana (American Sociological Association), Anaheim, CA. [Agosto], 2001.

ARROW, Kenneth. Social choice and individual values. New York: Wiley, 1951.

ARROW, Kenneth. Social choice and individual values. $2^{\text {nd }}$ Edition. New York: Wiley, 1963.

ARTHUR, W. Brian. Positive feedbacks in the economy. In: Scientific American (February), 1990, p. 92-99.

ARTHUR, W. Brian. Increasing returns and path dependence in the economy. Ann Arbor: University of Michigan Press, 1994.

BARDHAN, Pranab. The New Institutional Economics and Development Theory: A Brief Critical Assessment. In: World Development, 17 (9) [September], 1989, p. 1389-95. 
BARDHAN, Pranab. Deliberative conflicts, collective action, and institutional economics. In: Meier \& Stiglitz (eds.). Frontiers of Development Economics, 2001, p. 269-300.

BARRO, Robert. The determinants of economic growth: a cross-country empirical study. Cambridge, MA: MIT Press, 1997.

BENHABIB, Seyla. (Ed.). Democracy and difference; contesting the boundaries of the political. Princeton, New Jersey: Princeton University Press, 1996.

BAIERLE, Sergio. "OP ao Thermidor" Porto Alegre, Brasil. Dissertação de Mestrado não-publicada, 2001.

BIAOCCHI, Gianpaolo. From militance to citizenship: the workers party, civil society, and the politics of participatory governance in Porto Alegre, Brazil. Tese de Doutorado, Dept. of Sociology, University of Wisconsin-Madison. Madison, WI, 2001.

BIAOCCHI, Gianpaolo. Participation, Activism and Politics: The Porto Alegre Experiment and Deliberative Democratic Theory. In: Fung \& Wright. Deepening Democracy: institutional innovations in empowered participatory governance (no prelo), p. 47-84.

BLOMSTROM, Magnus; LIPSEY, Robert \& ZEJAN, Mario. Is fixed investment the key to economic growth? In: Quarterly Journal of Economics, 111 (1) [February], 1996, p. 269-76.

BONHAM, James \& REHG, William. Deliberative Democracy. Cambridge, MA: MIT Press, 1997.

BRANSON, William H \& Carl Jayarajah. Evaluating the impacts of policy adjustment. In: International Monetary Fund Seminar Series, 1 [January], 1995.

CHANG, Ha-joon. Kicking away the ladder: policies and insitutions for development in historical perspective. London (no prelo).

CHANG, Ha-Joon \& Peter Evans. The role of institutions in economic change. Trabalho apresentado na Conferência "The Other Canon and Economic Development", Oslo, Norway, August 14-15th, 2000. 
Sociologias, Porto Alegre, ano 5, no 9, jan/jun 2003, p. 20-63

CHENERY, H.; AHLUWALIA, M. S. et al. Redistribution with growth : policies to improve income distribution in developing countries in the context of economic growth. London: Oxford University Press, 1979.

CLARKE, George. More evidence on income distribution and growth. In: Journal of Development Economics, 47 (August), 1996, p. 403-427.

COHEN, Joshua \& Joel Rogers. Associations and Democracy. London: Verso, 1995.

DEININGER K \& Squire L . New ways of looking at old issues: Inequality and growth. In: Journal of Development Economics, 57 (2), 1998, p. 259-287.

DeLONG, Bradford \& Lawrence Summers. Equipment investment and economic growth. In: Quarterly Journal of Economics, 106 (2)[May], 1993, p. 445-502.

DOMAR, Evsey. Essays in the theory of economic growth. Oxford: Oxford University Press, 1957.

EASTERLY, William. The elusive quest for growth: economists' adventures and misadventures in the tropics. Cambridge, MA: MIT Press, 2001a.

EASTERLY, William. The failure of development. In: Financial Times, July 4, 2001b, p. 13.

ELSTER, Jon (Ed.). Deliberative Democracy. Cambridge: Cambridge University Press, 1998.

EVANS, P. State-Society Synergy: government action and social capital in development. Seção especial do World Developmen, 24 (6) [June], 1996.

EVANS, P. Embedded autonomy: States and industrial transformation. Princeton, NJ: Princeton University Press, 1995.

FEDOZZI, Luciano. Orçamento participativo: reflexões sobre a experiência de Porto Alegre. Porto Alegre: Tomo Editorial, 1997.

FISHLOW, Albert. Inequality, poverty and growth: where do we stand?. Conferência Anual do Banco Mundial sobre Economia de Desenvolvimento (Annual World Bank Conference on Development Economics). Washington DC: 
World Bank, 1995.

FRANKE, Richard W. \& Barbara H. Chasin. 1989. Kerala: radical reform as development in an Indian State. San Francisco, CA, The Institute For Food and Development Policy: Food First Development Report No. 6, October, 1989.

FUNG, Archon \& Erik Wright. Deepening Democracy: institutional innovations in empowered participatory governance. London: Verso (no prelo).

GENRO, Tarso \& Ubiratan de Souza. Orçamento participativo: a experiência de Porto Alegre. Porto Alegre: Fundação Perseu Abramo, 1997.

GOLDFRANK, Benjamin. Deepening Democracy through citizen participation? A Comparative analysis of three cities. American Political Science Association, Annual Meeting, August 2001.

GRIEF, Avner. 1994. Cultural beliefs and the organization of society: historical and theoretical reflections on collectivist and individualist societies. In: Journal of Political Economy, 102 (5)[October], p. 912-50.

GUTMAN, Amy \& Dennis Thompson. Democracy and Disagreement. Cambridge, MA: Harvard University Press, 1996.

HABERMAS, Jurgen. The structural transformation of the public sphere. T. Burger \& F. Lawrence (trans). Cambridge: MIT Press, 1962.

HABERMAS, Jurgen. The theory of communicative action (2 Volumes). Boston: Beacon Press, 1989,1991.

HELLER, Patrick. The labor of development: workers and the transformation of capitalism in Kerala, India. Ithaca, NY: Cornell University Press, 1999.

HELLER, Patrick. Degrees of Democracy: some comparative lessons from India. World Politics, 52 (July), 2000, p. 484-519.

HELLER, Patrick. Moving the State: the politics of democratic decentralization in Kerala, South Africa and Porto Alegre. Politics and Society, 29 (1) [March], 2001, p. 131-163. 
Sociologias, Porto Alegre, ano 5, no 9, jan/jun 2003, p. 20-63

HIRSCHMAN, Albert. Shifting involvements: private interest and public action. Princeton, NJ: Princeton University Press, 1981.

HODGSON, G. Economics and Institutions. Cambridge: Polity Press, 1988.

HOFF, Karla \& Joseph Stiglitz. Modern economic theory and development. In: Meier, Gerald \& Joseph Stiglitz. Frontiers of Development Economics, 2001, p. 389-460.

HOUTZAGER, Peter \& Mick Moore. Changing paths: the new politics of inclusion. Ann Arbor: University of Michigan Press (no prelo).

ISAAC, Thomas TM (com Richard Franke). Local Democracy and development: people's campaign for decentralized planning in Kerala. New Delhi: Left Word Books, 2000.

ISAAC, Thomas TM \& Patrick Heller. Decentralization, Democracy and development: the people's campaign for decentralized planning in Kerala. In: Fung \& Wright. Deepening Democracy: institutional innovations in empowered participatory governance (no prelo), p. 86-118.

JORGENSON, D. W.; GALLOP, F. \& FRAUMENI, B. Productivity and U. S. economic growth. Cambridge: Harvard University Press, 1987.

KANBUR, Ravi \& Lyn Squire. The evolution of thinking about poverty: exploring the interactions. In: Meier \& Stiglitz. Frontiers of development economics, 2001, p. 183-226.

KAPUR, Devesh. The new conditionalities of the international financial institutions. International Monetary and Financial Issues for the 1990s. Vol. VIII. New York and Geneva: Publicações das Nações Unidas, no. E.97.II.D.5, 1997.

KAPUR, Devesh. Risk and reward: agency, contracts, and the expansion of IMF conditionality. Resumo preparado para oficina em A Economia Política das Instituições Internacionais Monetárias e Financeiras (Political Economy of International Monetary and Financial Institutions), 2000.

KAPUR, Devesh \& Richard Webb. Governance-related conditionalities of 
the international financial institutions. G-24 Discussion Paper no. 6. United Nations: New York and Geneva, 2000 [http://www.g24.org/g24-dp6.pdf].

KILLICK, Tony. IMF programmes in developing countries. London: Routledge, 1995.

KIM, J \& L Lau. The sources of economic growth of the East Asian newly industrialized countries. Journal of Japanese and International Economies, 8, 1994, p. 235-271.

KIM, J \& L Lau. The role of human capital in the economic growth of the East Asian newly industrialized countries. Asian Pacific Economic Review, 1, 1995, p. 259-292.

KING, Robert G., \& Ross Levine. Capital fundamentalism, economic development, and economic growth. Carnegie-Rochester Conference Series on Public Policy 40, 1994, p. 259-292.

KREMER, Michael. The O-Ring theory of economic development. Quarterly Journal of Economics, 108 (August), 1993, p. 551-575.

LANDA, D. \& E.B. Kapstein., 2001. Review article: inequality, growth and Democracy. World Politics, 53 (1), p. 264-96.

LI, Hongyi \& H. Zou. Income inequality is not harmful for growth: theory and evidence. Review of Development Economics, 2 (3), 1998, p. 318-324.

LIJPHART, Arend. Patterns of Democracy: Government forms and performance in 36 Countries. New Haven: Yale University Press, 1999.

LIN, Kenneth S. \& Hsiu-Yun Lee. Can capital fundamentalism be revived? A general equilibrium approach to growth Accounting. In: G. Ranis et al. (eds.), The Political Economy of Comparative Development into the $21^{\text {st }}$ Century. Northhampton, MA: Edward Elgard, 1999, p. 77-105.

LIPTON, M. Land reform as commenced business: The evidence against stopping. World Development, 21 (4), p. 641-657.

Lucas, Robert E. On the Mechanics of Economic Development. Journal of Monetary Economics, 22 (July, 1988), 1993, p. 3-42. 
Sociologias, Porto Alegre, ano 5, no 9, jan/jun 2003, p. 20-63

MacADAM, D., S. Tarrow \& C. Tilly. Dynamics of Contention. New York/ Cambridge: Cambridge University Press, 2001.

MANSBRIDGE, Jane. Democracy and common interests. Social Alternatives, 8 (4), 1990, p. 20-25.

MEIER, Gerald \& James Rauch. Leading issues in economic development [7 $7^{\text {th }}$ Edition]. New York: Oxford University Press, 2000.

MEIER, Gerald \& Joseph Stiglitz. Frontiers of Development Economics. New York: Oxford University Press [World Bank], 2001.

NARAYAN, Deepa. The contribution of people's participation: evidence from 121 rural water supply projects. Environmentally Sustainable Development Occasion Paper Series, no. 1. Washington, DC: The World Bank, 1994.

NARAYAN, Deepa. Voices of the poor: can anyone hear us?. New York: Oxford University Press, 2000.

NOORBAKHSH, Farhad \& Alberto Paloni. Human capital and FDI inflows to developing countries: New empirical evidence. World Development, 29 (9) [September], 2001, p. 1593-1610.

NORTH, Douglass C. Structure and change in economic history. New York: Norton, 1981.

NORTH, Douglass C. The new institutional economics. Journal of Institutional and Theoretical Economics, 142, 1986, p. 230-37.

NORTH, Douglass C. Institutions, institutional change and economic performance. Cambridge, England: Cambridge University Press, 1990.

O'DONNELL, Guillermo. On the state, democratization and some conceptual problems: A Latin American view with glances at some postcommunist countries. World Development, v. 21, n. 8 (1993), p. 1355-1369.

OSTROM, Elinor. Governing the commons: the evolution of institutions for collective action. New York: Cambridge University Press, 1990. 
OSTROM, Elinor. Incentives, rules of the game, and development. In: Proceedings of the World Bank Annual Conference on Development Economics 1995. Washington, DC: The World Bank, 1995.

OSTROM, Elinor. Decentralization and development: The New Panacea. In: Keith Dowding, James Hughes, \& Helen Margetts (ed.). Challenges to Democracy: Ideas, Involvement and Institutions (The PSA Yearbook 2000), p. 237-256. New York: Palgrave Publishers, 2001.

PERSSON T \& Tabellini G. Is inequality harmful for growth?. American Economic Review, 84, 1994, p. 600-621.

PIERSON, Paul. Path dependence, increasing returns and the study of politics. Working Paper \#7, Program for the Study of Germany and Europe, Harvard University. Cambrdige, MA, 1997.

PISTOR, Katharina. The standardization of law and its effect on developing economies [G-24 Working Paper]. New York: United Nations/UNCTAD, 2000.

POZZOBONO, Regina. Porto Alegre: os desafios da gestão democrática. São Paulo: Instituto Polis, 1998.

PRZEWORSKI, Adam et al. Democracy and development: political institutions and well-being in the World 1950-1990. New York: Cambridge University Press, 2000.

PRZEWORSKI, Adam \& Fernando Limongi. Political regimes and economic growth. Journal of Economic Perspectives, 7 (3) [Summer], 1993, p. 51-70.

PUTNAM, Robert. Making Democracy Work: civic traditions in Modern Italy. Princeton: Princeton University Press, 1993.

PUTNAM, Robert. Bowling alone: the collapse and revival of American Community. New York: Simon and Schuster, 2000.

RAVALLION, Martin. Does Aggregation hide the harmful effects of inequality on growth? Economic Letters, 61, 1998, p. 73-77.

RODRIK, Dani. Institutions for high-quality growth: what are they and how to acquire 
Sociologias, Porto Alegre, ano 5, no 9, jan/jun 2003, p. 20-63

Them. Trabalho apresentado na conferência do FMI sobre as Reformas da Segunda Geração (Second-Generation Reforms), Washington DC. November 8-9, 1999a.

RODRIK, Dani. The New Global Economy and developing countries: making openness work. [Policy Essay no. 24] Washington, DC: Overseas Development Council [Johns Hopkins University Press], $1999 b$.

ROMER, Paul M. Increasing returns and long run growth. Journal of Political Economy, 94 [October], 1986, p. 1002-1037.

ROMER, Paul M. Endogenous technological change. Journal of Political Economy, 98, 1990, p. 71-102.

ROMER, Paul M. Two strategies of economic development: using ideas and producing ideas. In: Proceedings of the 1992 World Bank Annual Conference on Economic Development. World Bank: Washington, DC., 1993a, p. 63-91.

ROMER, Paul M. Idea Gaps and object gaps in economic development. Journal of Monetary Economics, 32, 1993b, p. 543-573.

ROMER, Paul M. The origins of endogenous growth. J. of Econ. Perspects, 8 (1), 1994 [Winter], p. 3-22.

RUESCHMEYER, Dietrich, Evelyne Stephens \& John Stephens. Capitalist Development and Democracy. Cambridge, England: Polity Press and Chicago: University of Chicago Press, 1992.

SANTOS, Boaventura de Sousa. Participatory budgeting in Porto Alegre: toward a redistributive democracy. Politics and Society, 26 (4) [Dec.], 1998, p. 461-510.

SCHNEIDER, Aaron \& Benjamin Goldfrank. Budgets and ballots in Brazil: participatory budgeting from the City to the State. Trabalho apresentado no Encontro Anual da Associação Americana de Ciência Política (American Political Science Association), [August] 2001.

SEN, Amartya. Rationality and social choice. American Economic Review, Papers and Proceedings 85 [Presidential Address], 1995, p. 1-24.

SEN, Amartya. Development as freedom. New York: Alfred A. Knopf, 1999a. 
SEN, Amartya. The possibility of social choice. American Economic Review. Papers and Proceedings 89, 1999b, p. 349-378 [Nobel Lecture].

SEN, Amartya. What development is about. In: Meir \& Siglitz, Frontiers of Development Economics, 2001.

SOLOW, Robert. Technical change and the aggregate production function. Review of Economics and Statistics, 39, 1957, p. 312-320.

SRINIVASAN, T. N. Human development: a new paradigm or reinvention of the wheel. American Economic Review. Papers and Proceedings 84, 1994, p. 238-243.

STEWART, Frances. Income distribution and development. Trabalho preparado para UNCTAD X High Level Round Table on Trade and Development: Directions for the Twenty-first Century. Bangkok, Thailand, 2000.

STEWART, Frances \& Severine Deneulin. Amartya Sen's contribution to development thinking. Studies in Comparative International Development (no prelo).

STREETEN, Paul. Human development: means and ends. American Economic Review, 84 (2), 1994, p. 232-237.

STREETEN, P. P.; S. J. Burki et al. First things first, meeting basic human needs in developing countries. New York: Oxford University Press, 1981.

TAYLOR, Charles. Irreducible social goods. In: Philosophical Arguments. Cambridge, MA: Harvard University Press, 1995, p. 127-145.

THARAMANGALAM, Joseph. The perils of development without economic growth: The development debacle of Kerala, India. Bulletin of Concerned Asian Scholars, 30 (1), 1998.

UPHOFF, Norman, John M. Cohen \& Arthur Goldsmith. Feasibility and application of rural development participation: a state of the art paper. Ithaca: Rural Development Committee, Center for International Studies, Cornell University, 1979.

UPHOFF, Norman. Local Institutional Development: An Analytical Sourcebook with Cases. West Hartford, CT: Kumarian Press for Cornell University, 1986. 
WADE, Robert. Showdown at the World Bank. New Left Review, JanuaryFebruary 7, 2001a, p. 124-137.

WADE, Robert. Making the world development report 2000: attacking poverty. World Development, 29 (8) [August], 2001b, p. 1435-1441.

WOOLCOCK, Michael. Social capital and economic development: towards a theoretical synthesis and policy framework. Theory and Society, 27 (1), 1997, p. 157.

World Bank (IBRD). 2000-2001 World Development Report: Attacking Poverty. New York: Oxford University Press.

YOUNG, Alwyn. The tyranny of numbers: confronting the statistical realities of the East Asian growth experience. Quarterly Journal of Economics (August), 1995, p. 641-680.

YUSUF, Shahid \& Joseph Stiglitz. Development issues: settled and openin. In: Meier 


\section{Resumo}

A teoria econômica moderna foi além do "fundamentalismo do capital". Nas palavras de Hoff e Stiglitz (2001, p. 389), "o desenvo/vimento não é mais visto primariamente como um processo de acúmulo de capital, mas antes como um processo de mudança organizacional". Essa percepção possibilitou uma "virada institucional" na teoria do desenvolvimento ao enfatizar o papel de idéias e das instituições enquanto determinantes das possibilidades para o acúmulo de capital, ao invés do oposto. Tanto a "nova teoria do crescimento" quanto o "novo institucionalismo" de Douglass North são exemplos dessa virada institucional. Infelizmente, a "virada institucional" tem sido utilizada de modo perverso por formadores de políticas globais. A visão globalmente dominante é a de que, por serem as instituições tão importantes, por conseguinte, um planejamento institucional baseado em versões idealizadas de instituições anglo-americanas deve ser uniformemente imposto aos países ao Sul do globo para que se desenvolvam.

De forma não surpreendente, essa visão falhou na prática. Perspectivas alternativas propostas por Rodrik e Sen defendem que o desenvolvimento tem poucas possibilidades de ter êxito a menos que a mudança institucional esteja alicerçada na tomada de decisões local. Essa é a visão explorada neste trabalho. O estado de Kerala na Índia e a cidade de Porto Alegre no Brasil são utilizados como casos concretos.

Palavras-chave: teoria do crescimento econômico, desenvolvimento, instituições, democracia, globalização, capacidades, Kerala, Porto Alegre. 